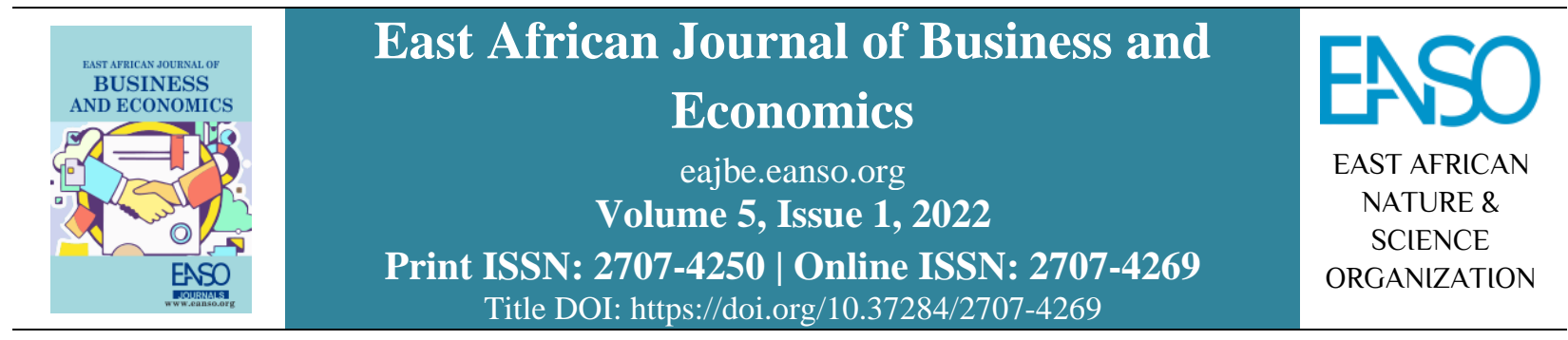

Original Article

\title{
Reward and Compensation Management Initiatives on Employee Performance: An Evidence of Organization Development Initiatives.
}

\author{
Francis Lipuku ${ }^{1 *}$, Dr. Hellen Sang, $P h D^{1}$, Dr. Williter Rop, $P h D^{1}$ \\ ${ }^{1}$ University of Kabianga. P. O. Box 2030-20200, Kericho, Kenya. \\ * ORCID: https://orcid.org/0000-0002-5221-8533; Correspondence email: flipuku@ gmail.com.
}

Article DOI: https://doi.org/10.37284/eajbe.5.1.552

\section{Date Published: ABSTRACT}

15 February 2022 Organisational development (OD) interventions are structured programs designed to solve a problem, which enables the organisation to attain its goals which are

Keywords: critical in an age where organisation performance and return on investors is important. Employee performance is how employees fulfil their duties and

Reward, complete the tasks assigned at the workplace on time. Increased employee Compensation performance translates to higher output hence higher returns to factors of Initiative, production. It is on this note the paper aims to determine the relationship between Employee profit and compensation management and employee performance in not-for

Performance, Rift region. The study adopted a quantitative research design where a target Correlational population of 500 respondents was used. The findings indicated that reward and Research Design, compensation initiatives had a significant positive relationship with employee Kenya. performance $(\beta=0.395 ; p=0.000<0.05)$. The study recommends that there is a need for organisations to have proper rewards and compensation in place to enhance employee performance. More emphasis should be directed to reward and compensation because it is the main contributors to employee performance.

\section{APA CITATION}

Lipuku, F., Sang, H., \& Rop, W. (2022). Reward and Compensation Management Initiatives on Employee Performance: An Evidence of Organization Development Initiatives. East African Journal of Business and Economics, 5(1), $72-79$. https://doi.org/10.37284/eajbe.5.1.552.

\section{CHICAGO CITATION}

Lipuku, Francis, Hellen Sang, and Williter Rop. 2022. "Reward and Compensation Management Initiatives on Employee Performance: An Evidence of Organization Development Initiatives". East African Journal of Business and Economics 5 (1), 72-79. https://doi.org/10.37284/eajbe.5.1.552.

\section{HARVARD CITATION}

Lipuku, F., Sang, H., \& Rop, W. (2022) "Reward and Compensation Management Initiatives on Employee Performance: An Evidence of Organization Development Initiatives", East African Journal of Business and Economics, 5(1), pp. 72-79. doi: 10.37284/eajbe.5.1.552.

72 | This work is licensed under a Creative Commons Attribution 4.0 International License. 


\section{IEEE CITATION}

F. Lipuku, H. Sang, \& W. Rop, "Reward and Compensation Management Initiatives on Employee Performance: An Evidence of Organization Development Initiatives", EAJBE, vol. 5, no. 1, pp. 72-79, Feb. 2022.

\section{MLA CITATION}

Lipuku, Francis, Hellen Sang, and Williter Rop. "Reward and Compensation Management Initiatives on Employee Performance: An Evidence of Organization Development Initiatives". East African Journal of Business and Economics, Vol. 5, no. 1, Feb. 2022, pp. 72-79, doi:10.37284/eajbe.5.1.552.

\section{INTRODUCTION}

Organisational development comprises values, behavioural science-based theories, techniques, and strategies designed to deliberately bring change at the organisational work environment to improve individual growth and improve performance of the entity through the mind shift of people within the organisation on the job behaviours (Porras and Roberston, 2015). Organisation development initiatives entail reward systems, value, and compensation strategies that an organisation can adopt to motivate employees as well as improve performance. Initiatives in support of employee performance are important, but unfortunately, employee satisfaction and performance remain elusive. Many studies have been done to evaluate the significance of individual interventions under organisation development which are human processes, organisation cultures, organisation structures, and strategic interventions on employee performance (Almasaeid \& Anagreh, 2020). The existing problem, therefore, would be to look at how all these factors combined affect employee performance. Private non-profit organisations comprising of NGOs and community-based selfhelp groups, among others, which came into existence alleviate societal hardships and facilitate the delivery of social services to the marginalised. Even with the exponential growth in number and activities, the not-for-profit sector remains scantily understood and invisible to policymakers, the media, and academics in Kenya. This provides a management dilemma in defining standards of optimal operations; therefore, this study will help shed light on the applicability of organisation development initiatives to Not-for-profit entities and their influence on the performance of employees. The study sought to determine the existing relationship between reward and compensation initiatives and employee performance in not-for-profit organisations in South Rift, Kenya.

Human resource management focuses on ensuring effective management of the people within an entity to help the organisation gain a competitive advantage which is achieved through maximising employee performance towards the attainment of organisations' strategic objectives. Human resource management focuses on the design of policies and systems within an organisation to facilitate people's management. The subject of employee performance has been widely studied, with most of the studies focusing on the primary function. In the real world, however, employee performance will be affected by a myriad of factors working in unison. The concept of organisation development provides an ideal platform to subject human resource management, human processes, technology and structure, and strategic interventions to the comparative evaluation of how they affect employee performance.

The objective of the processes is to bring improvement in the synergy within the organisational culture, processes, structure, people, and strategies and culminates in the rollout of new and innovative organisational solutions that develop the entity's self-renewing capability. All these initiatives are aimed at improving the organisation; human resources being the core of these gives impetus to the study where attempts are made to provide information about the link between the initiatives and employee performance, if any. An organisational culture entails the behaviours, 
beliefs, and unwritten customs that determine the "Norm" for decision-making, structure, and power within organisations. This, therefore, defines how things are done within an organisation, focusing on coping mechanisms that facilitate integration and individual excellence among employees (Aina \& Atan, 2020).When an organisation has a strong culture, employees are inclined to action because they believe that it is the right thing to be done and are convinced that there is a reward for what they do. Human process intervention focuses on employees understanding their behaviour and others' behaviour to improve the benefits through the decision making and problem-solving to accomplish goals within an entity and this comprises process consultation, team building, and sensitivity training measures. The study will therefore provide findings that shall be used by an organisation at the strategic level when designing organisation development initiatives touching on employee performance. The main objective is to determine the relationship between reward and compensation initiatives and employee performance in not-for-profit organisations in the south Rift.

\section{LITERATURE REVIEW}

\section{Theoretical Review}

The two-factor theory, though related to Maslow's hierarchy, it addresses more elements in measuring the motivation of individuals at the workplace. The theory postulates that meeting the extrinsic or hygiene factors (lower-level needs) of employees is not sufficient motivation for them to exert more effort; it only prevents individuals from getting dissatisfied. Intrinsic or motivation factors (higherlevel needs) needs to be applied in motivating employees. Organisations need to make use of the theory by understanding that focusing on meeting the extrinsic or hygiene factors of employees alone prevents them from being dissatisfied but does not motivate them towards contributing increased effort to enhance performance. Organisations that want to motivate employees should focus on enhancing intrinsic or motivation factors (Robbins, 2009).

This theory intimates that employee satisfaction is a factor of motivators (recognition, achievement, staff satisfaction by the work they do, responsibility, and opportunities for advancement and growth), whereas employee dissatisfaction is an outcome of hygiene elements (general management, organisation policies, working conditions and the individual staff relationship the managers).

The theory presents two elements of human needs; the inherent primitive need as animals to avert pain and the human desire for growth psychologically. Herzberg surveyed by carrying out several interviews to elicit responses to questions posed to participants. Herzberg established from the study that replies from respondents' when feeling great regarding their work differed greatly from responses received when employees are unhappy about their jobs. Better pay and other compensation-related packages make employees like the results of their work, attributing this to the intrinsic factors. Employees who are dissatisfied, on the contrary, attribute this to the extrinsic factors comprising their supervisors, pay, and organisation policies and conditions at the workplace (Nyambegera \& Gicheru, 2016).The theory is of great significance to the study as it highlights the two factors which determine performance at the workplace. The first is the factor extrinsic to work which includes remuneration and career progression; the secondfactors being intrinsic to work which comprise commendation and acknowledgement. In the context of this study, the design of compensation packages for employees focusing on both intrinsic and extrinsic rewards is anticipated to affect the performance of work by employees hence a pointer to individual performance.

\section{Empirical Review}

A study conducted by Njoroge and Kwasira (2015) sought to determine the influence of compensation 
and reward on the performance of employees at Nakuru County Government. The study findings indicated that there was a positive relationship between compensation and employee reward on performance in Nakuru county government. These findings provide credence to the study's pursuit of confirming whether compensation positively impacts employee performance. The study was conducted based on the existing reward system; our attempt will therefore be to look at the strategies which are more about the plans for the future rather than practices in place. Extrinsic rewards refer to employee compensation or rewards paid out in the form of fringe benefits and other tangible benefits to employees by an organisation for attaining set objectives or set out by the organisation (Farooqui \& Nagendra, 2014).

Extrinsic rewards paid out by Not-for-profit organisations are made as salary and wages, vacation payment, annual leave payment, and annual bonuses (Abdullah \& Siti-Nabiha, 2012). Wages and salaries are payments made monthly by employers to employees for work done as per the existing contract of employment (Boselie et al., 2015). Salaries and wages are terms used in alternation about financial compensation awarded to employees by employers. Salaries and wages are different; Salaries are payments or compensation paid out to employees on permanent terms or those on long-serving contractual employees. Wages on the other hand are payments to short-term engagements or casual labourers (Pratheepkanth, 2011).

Pratheepkanth (2011) further postulates these payments enhance employee performance to only up to a certain threshold; above this thresh hold they cease to be motivational or have the capability to enhance employee performance. Salaries will enhance employee performance when their needs are primarily security and financial stability (Dobre, 2013). When employees get to a level where they feel financially stable and secure, salaries or wages cease to be a factor that motivates or enhances their commitment or performance levels within the organisation. Employee compensation is aimed at motivating the workforce of an organisation to enhance performance. The mix and type of compensation strategies to be adopted by an organisation still pose a challenge. Studies have, however, demonstrated that compensation has a positive impact both on the health of employees and safety at the workplace.

Employee reward and compensation increase employee loyalty to the organisation and enhance engagement at the workplace which is a critical element of employee performance at the workplace (Lawler \& Worley, 2016; Osan et al., 2012). Motivated employees are not only satisfied in the workplace but also appreciate when their wants are fulfilled. The reason for the use of variety in compensation types is because employees are motivated to improve performance and also keep the employees able to meet both their financial and non-financial needs, absence of inadequacy of this tempts employees to leave the organisation (Azasu, 2017).

Employee preferences are vast with some having preference for intrinsic rewards in terms of praise and recognition for certain work accomplishments, others, however, are happy with extrinsic rewards in terms of salaries, bonuses, and other incentives offered to employees to enhance their performance (Sajuyigbe et a., 2013). It is, therefore, emerges that diversity as a method of employee compensation and rewards motivate them and spur improved performance at the workplace. This study, therefore, sought to establish how compensation design initiatives as a construct of organisation design affect employee performance.

This study examined the issues of organisational development and employee performance (concerning goals) in detail with strict consideration on organisation development initiatives as an effective tool for managing change to enhance employee performances recorded by authors and 
theorists. The study sought therefore to assist in determining how much consideration should be given to the design of compensation plans during organisation development initiatives as part of stimulating employee performance.

\section{RESEARCH METHODOLOGY}

This study adopted a quantitative survey design. The study was carried out within South Rift counties of Bomet, Kericho, and Nandi targeting not-forprofit organisations within the region. The sampled not-for-profit organisations are I Choose life $(\mathrm{K})$ in Bomet, Konnect Youth Centre, Walter Reed Project and Live with Hope centre within Kericho and AMPATH within Nandi County. The target population was 500 employees across the 4 organisations comprising both management and non-management staff; of these, 250 were from the Walter reed program, 70 from I choose life in Bomet County, 110 from the Konnect youth consortium and 70 from AMPATH in Nandi County.

A multistage sampling procedure was employed in the study. In the first stage, a purposive sampling procedure was employed to select the four institutions in the three Counties within the south rift valley comprising Bomet, Kericho, and Nandi hence the institutions above. In the second stage, the stratified sampling technique helped select respondents who took part in the study. A sample of 109 respondents from Walter reed program, 30 from I Choose Life in Bomet county, 48 from Konnect youth consortium, and 30 from AMPATH, respectively making a sample of 217 respondents. The study employed questionnaires to collect primary data. Descriptive statistics were used to describe patterns and general trends in a set of data. A linear regression model was considered appropriate as an inferential tool that established the relationship between the variables. A research permit was obtained from the University of Kabianga IERC. The letter was used to apply for a permit from the National Commission of Science, Technology, and Innovation (NACOSTI). Ethical standards pertaining to the respondents and conduct of research were adhered to throughout the research process.

\section{RESULTS AND DISCUSSIONS}

To determine the relationship between reward and compensation initiative and employee performance of the not-for-profit making organisations in South Rift Kenya, descriptive analysis was conducted. The analysis entails descriptive statistics results for reward and compensation initiative were analysed using mean and standard deviation. The summary results are presented in Table 1.

Table 1: Reward and compensation Management initiatives

\begin{tabular}{|c|c|c|c|c|c|}
\hline & $\mathbf{N}$ & Min & Max & Mean & Std. Dev. \\
\hline $\begin{array}{l}\text { As per your experience, does the existing compensation } \\
\text { structure reward effort for employees? }\end{array}$ & 207 & 1.00 & 5.00 & 3.2899 & 1.01591 \\
\hline $\begin{array}{l}\text { As per your experience, does the existing pay structure } \\
\text { equitably compensate all staff (senior to junior) within the } \\
\text { organisation }\end{array}$ & 207 & 1.00 & 5.00 & 3.1208 & .95017 \\
\hline $\begin{array}{l}\text { Does the existing salary structure decision-making system } \\
\text { within the organisation support you as you carry out } \\
\text { assigned tasks? }\end{array}$ & 207 & 1.00 & 5.00 & 3.1981 & .92663 \\
\hline $\begin{array}{l}\text { Do you agree that the current Pay structure within the } \\
\text { organisation compares well with peers in the industry? }\end{array}$ & 207 & 1.00 & 5.00 & 3.0531 & 1.15837 \\
\hline
\end{tabular}

76 This work is licensed under a Creative Commons Attribution 4.0 International License. 


\begin{tabular}{llllll}
\hline & N & Min & Max & Mean & Std. Dev. \\
\hline $\begin{array}{l}\text { Does the reward and benefits package offered by the } \\
\text { organisation contribute to your long service within the } \\
\text { organisation? }\end{array}$ & & 1.00 & 5.00 & 3.2222 & 1.07887 \\
\hline $\begin{array}{l}\text { Does the non-financial reward program within your } \\
\text { organisation increase your level of performance? }\end{array}$ & & & & & \\
\hline Valid N (listwise) & 207 & 5.00 & 3.1353 & 1.10650 \\
\hline
\end{tabular}

Table 1 indicated that the respondents agreed $(M=$ 3.2899; $S D=1.01591$ ) that according to their experience the existing compensation structure reward effort for employees. The respondents also agreed $(M=3.1208 ; S D=0.95017)$ that the existing pay structure equitably compensates all staff (senior to junior) within the office. The majority of the respondents $(M=3.1981 ; S D=0.92663)$ agreed that the existing salary structure decision-making system within the organisation supported them as they carried out assigned tasks. Further, the respondents agreed that the current pay structure within the organisation compares well with peers in the industry $(M=3.0531 ; S D=1.15837)$. The respondents also agreed that the reward and benefits package offered by the organisation contributed to their long service within the organisation $(M=$ $3.2222 ; S D=1.07887$ ) and finally, they also agreed that the non-financial reward program within your organisation increases your level of performance $(M$ $=3.1353 ; S D=1.10650)$. The findings of this study on reward and compensation are similar to the study done by Njoroge and Kwasira (2015) which established that there is a positive relationship between reward and compensation on employee performance.

Employee performance was analysed using mean and standard deviation based on a Likert scale of 1 to 5 from strongly disagree to strongly agree. The results summarised were presented in Table 2.

Table 2: Influence of Reward and Compensation Initiatives on Employee Performance

\begin{tabular}{|c|c|c|c|c|c|}
\hline & $\mathbf{N}$ & Min & Max & Mean & Std. Dev. \\
\hline $\begin{array}{l}\text { As per your experience, do the current initiatives contribute } \\
\text { to increased output at the workplace? }\end{array}$ & 207 & 1.00 & 5.00 & 3.7053 & .77905 \\
\hline $\begin{array}{l}\text { Do you feel motivated to come to work regularly on time by } \\
\text { current management initiatives? }\end{array}$ & 207 & 1.00 & 5.00 & 3.6715 & 1.05126 \\
\hline $\begin{array}{l}\text { Does the existing communication framework allow for free } \\
\text { dissemination of information between staff and } \\
\text { management? }\end{array}$ & 207 & 1.00 & 5.00 & 3.6425 & .91785 \\
\hline $\begin{array}{l}\text { Does the existing organisation structure facilitate you } \\
\text { carrying out assigned tasks with ease? }\end{array}$ & 207 & 1.00 & 5.00 & 3.9227 & .79673 \\
\hline $\begin{array}{l}\text { Does the organisation have training programs that help in } \\
\text { enhancing your skills to improve your performance at work? }\end{array}$ & 207 & 1.00 & 5.00 & 3.7391 & .87554 \\
\hline $\begin{array}{l}\text { Do the current initiatives by management encourage you to } \\
\text { stay longer with the organisation? }\end{array}$ & 207 & 1.00 & 5.00 & 3.5217 & .93905 \\
\hline Valid N (listwise) & 207 & & & & \\
\hline
\end{tabular}

77 | This work is licensed under a Creative Commons Attribution 4.0 International License. 
The findings outlined in Table 2 indicate that the majority of the respondents agreed $(M=3.7053 ; S D$ $=0.77905)$ that the current initiatives contribute to increased output at the workplace. The majority of the respondents $(M=3.6715 ; S D=1.05126)$ agreed that they felt motivated to come to work regularly on time by current management initiatives. The respondents also agreed $(M=3.6425 ; S D=$ 0.91785) that the existing communication framework allowed for free dissemination of information between staff and management. Similarly, the respondents agreed $(M=3.9227 ; S D$
$=0.79673$ ) that the existing organization structure facilitates carrying out assigned tasks with ease, and also, they agreed $(M=3.7391 ; S D=0.87554)$. Finally, many of the respondents agreed that the organisation had training programs that helped employees in enhancing their skills to improve their performance.

Correlation analysis was done to ascertain interrelationship between variables at a 5\% significant level. The summary results are presented in Table 3.

Table 3: Correlation coefficients

\begin{tabular}{llll}
\hline & & $\begin{array}{l}\text { Reward and Compensation } \\
\text { Initiatives }\end{array}$ & $\begin{array}{l}\text { Employee } \\
\text { Performance }\end{array}$ \\
\hline $\begin{array}{l}\text { Reward and Compensation } \\
\text { Initiatives }\end{array}$ & Pearson Correlation & 1 & $.698^{* *}$ \\
& Sig. (2-tailed) & & .000 \\
& $\mathrm{~N}$ & & 207 \\
\hline
\end{tabular}

The findings in Table 3 indicated that reward and compensation initiatives had a strong positive and significant relationship $(r=0.698, p=0.000<0.05)$ with employee performance. Reward and compensation initiatives had positive correlation coefficients indicating that their increase contributed to an increase in employee performance on the non-profit making organisations.

\section{CONCLUSIONS AND RECOMMENDATIONS}

\section{Summary}

Reward and compensation offered by the organisation contributed to their long service within the organisation. Non-financial reward program within your organisation increases your level of performance. According to the existing pay structure, equitably compensates all staff (senior to junior) within the office. Hence reward and compensation ensured that the existing salary structure decision-making system within the organisation supported them as they carried out assigned tasks. Further inferential analysis revealed that there was a strong significant relationship between reward and compensation initiative and employee performance.

\section{Conclusions}

The conclusion of this study is presented based on findings obtained with respect to study objectives. This study, therefore, concludes that organisational culture is a moderate factor influencing employee performance. Despite the significant relationship, there is a weak positive significant relationship with employee performance. The findings on reward and compensation are consistent with all the indicators of employee performance and the results are supported by empirical studies which are that reward and compensation are major and main drivers of employee performance.

\section{Recommendations}

The researcher recommends further studies be conducted on the same research topic but adopt different independent variables apart from the ones

78 This work is licensed under a Creative Commons Attribution 4.0 International License. 
that have been used in this study. Since the current study determined to establish the relationship between organisation development initiatives and employee performance in Not-for-profit organisations in Kenya and more especially in the South Rift region, there is a need to conduct a similar study in other regions to determine if the same results will be obtained.

\section{REFERENCES}

Abdullah, Z., \& Siti-Nabiha, A. K. (2012). Leadership and change management: A case study of Pemancar. Asian Case Research Journal, 16(01), 115-132.

Aina, R. \& Atan, T. (2020). The impact of implementing talent management practices on sustainable organizational performance. Sustainability. 12: 1-21.

Almasaeid, T. \& Anagreh, S. (2020). Organizational Development Interventions to Solve Performance Management Challenges. Journal of University of Shanghai for Science and Technology. 22(11): 1744-1760.

Azasu, S. (2009). Rewards and performance of Swedish real estate firms. Compensation \& Benefits Review, 41(4), 19-28.

Boselie, P., Dietz, G., \& Boon, C. (2005). Commonalities and contradictions in HRM and performance research. Human resource management journal, 15(3), 67-94.

Dobre, O. I. (2013). Employee motivation and organisational performance. Review of applied socio-economic research, 5(1), 53-60.

Farooqui, M. S., \& Nagendra, A. (2014). The impact of person organisation fit on job satisfaction and performance of the employees. Procedia economics and Finance, 11, 122-129.
Njoroge, S. W. \& Kwasira, J. (2015). Influence of compensation and reward on performance of employees at Nakuru County Government. IOSR Journal of Business and Management, 17(11), 87-93.

Nyambegera, S. \& Gicheru, C. (2016). Extrinsic and Intrinsic Factors Influencing Employee Motivation: Lessons from AMREF Health Africa in Kenya. International Journal of Business and Social Research. 6(9), 20-31.

Porras, S. \& Robertson, D. (2015). Model Approaches to Managing Organizational Change.

Pratheepkanth, P. (2011). Reward system and its impact on employee motivation in commercial bank of Sri Lanka plc, in Jaffna district. Global Journal of management and business research, 11(4), 0975-5853.

Robbins, S. (2009). Organisational behaviour, $13^{\text {th }}$ Edition. USA. McGraw

Sajuyigbe, A. S., Olaoye, B. O., \& Adeyemi, M. A. (2013). Impact of reward on employees performance in a selected manufacturing companies in Ibadan, Oyo State, Nigeria. International Journal of Arts and Commerce, 2(2), 27-32.

San, O. T., Theen, Y. M., \& Heng, T. B. (2012). The reward strategy and performance measurement (evidence from Malaysian insurance companies). International Journal of Business, Humanities and Technology, 2(1), 211-223.

Worley, C. G., \& Lawler, E. E. (2010). Built to change organisations and responsible progress: Twin pillars of sustainable success. In research in organisational change and development. Emerald Group Publishing Limited.

79 | This work is licensed under a Creative Commons Attribution 4.0 International License. 